\title{
Editorial-the 4th International Workshop on Modeling the Ocean (IWMO 2012)
}

\author{
Lie-Yauw Oey • Yasumasa Miyazawa $\cdot$ Hidenori Aiki • \\ Yukio Masumoto • Tal Ezer • Takuji Waseda
}

Received: 30 September 2013 / Accepted: 1 October 2013 / Published online: 25 October 2013

(C) Springer-Verlag Berlin Heidelberg 2013

The 4th International Workshop on Modeling the Ocean (IWMO; http://Www.jamstec.go.jp/frcgc/jcope/htdocs/e/ iwmo2012.html) was held on May 21-24, 2012 in the vibrant city of Yokohama on the Tokyo Bay, Japan. The Workshop was hosted by Japan Agency for Marine-Earth Science and Technology (JAMSTEC) - the home of the famous "Earth Simulator" - one of the world's most powerful supercomputers dedicated for simulating the complex interactive processes of the earth and its environment. Over 100 researchers worldwide participated in the Workshop, which included two keynote

\footnotetext{
Responsible Editor: Jörg-Olaf Wolff

L.-Y. Oey

Institute of Hydrological and Oceanic Sciences,

National Central University, Jhongli, Taiwan

L.-Y. Oey $(\triangle)$

Atmospheric and Oceanic Science Program,

Princeton University, Princeton, NJ 08544, USA

e-mail: lyo@princeton.edu

Y. Miyazawa $\cdot$ H. Aiki

Japan Agency for Marine-Earth Science and Technology

(JAMSTEC), Yokohama City, Kanagawa, Japan

Y. Masumoto

Department of Earth and Planetary Science,

The University of Tokyo, Tokyo, Japan

Y. Masumoto

Japan Agency for Marine-Earth Science and Technology

(JAMSTEC), Yokohama, Kanagawa, Japan

T. Ezer

Department of Ocean, Earth and Atmospheric Sciences,

Old Dominion University, Norfolk, VA, USA

T. Waseda

Department of Ocean Technology Policy and Environment,

The University of Tokyo, Chiba, Japan
}

lecturers, by Professor Mellor of Princeton University and Professor Yamagata of the University of Tokyo, and more than 80 oral presentations and 20 posters. The topics covered in the Workshop, as in the past IWMO's, are wide-ranging, from small-scale waves and estuarine processes to large-scale eddy and multi-decadal climate dynamics. In part thanks to the generosity of the host, a new record of 30 graduate students and postdocs participated in the Outstanding Young Scientist Award Competition, some with truly outstanding presentations of top scientific rigors.

The collection of 11 papers in this Topical Collection was selected from a total of 22 originally submitted after they underwent the usual process of reviews and revisions. There were at least two reviewers for each paper, but a few submissions had more. The reviews were solicited from both the Workshop attendees and the scientific community at large.

The subjects of papers in this Topical Collection include two on regional processes (Ezer and Oey 2013; Miyama and Miyazawa 2013), three on surface and upper-layer physics (Goh and Noh 2013; Mellor 2013; Ponte and Klein 2013), one on global modeling (Exarchou et al. 2012), three on coastal processes (Gao et al. 2013; Lu et al. 2013; Wang et al. 2013a), and two on analyses of model outputs (Wang et al. 2013b; Wu and Wang 2013).

Ezer and Oey (2013) use the results of high-resolution numerical experiments based on the Princeton Ocean Model (POM) of the Bering Sea (Ezer and Oey 2010) to study the dynamics of strait flows. Three distinct categories of strait dynamics are identified: shallow passages with near barotropic flows, wide passages which are driven by mesoscale eddies, and deep passages which have persistent baroclinic currents with deep return flows. Universal relations are found between the radius of deformation of each strait and the observed variability. Empirical Orthogonal Function (EOF) analyses reveal the spatial structure and forcing of the strait flows. The model shows that mesoscale variability in the Bering Sea originate from two 
different sources, a remote origin from variability in the Alaskan Stream that enters the Bering Sea through the Aleutian passages and a local origin from the interaction of currents with the Bowers Ridge in the Aleutian Basin.

Miyama and Miyazawa (2013) address why and how the Kuroshio is observed to accelerate as it flows past Cape Shionomisaki at the most southern tip of the island of Honshu, Japan. They demonstrate that the high-resolution JCOPE2 model outputs show acceleration only when the Kuroshio is in a non-large-meander state as well as when the upstream speed is sufficiently high. Using the hydraulic control theory, the authors analytically demonstrate that the key to explaining the acceleration is the existence of a bottom topographic ridge which juts off the cape where the shelf is narrowest. The ridge acts as a control point where flow becomes critical, and downstream of which flow accelerates to become supercritical.

Goh and Noh (2013) examine the influence of the Coriolis force on the formation of the seasonal thermocline using a large eddy simulation. The results indicate that Coriolis plays an important role in inhibiting downward heat and momentum transport in the high-latitude ocean, whereas heat and momentum propagate to deeper layers without forming a well-defined thermocline in the equatorial ocean. Their results confirm the hypothesis used in previous mixed-layer models that the depth of the seasonal thermocline decreases with the Coriolis parameter $f$.

Mellor (2013) provides a review of the theory of interaction of surface gravity waves and three-dimensional ocean currents, and applied it to the classic problem of waves incident on a sloping beach. If vertically integrated equations were used together with the assumption of negligible advection terms in the momentum equations, the classic elevation set-down is obtained (Longuet-Higgins and Stewart 1964; Phillips 1977). In the fully three-dimensional current-wave interaction model, however, the assumption breaks down as the current is an order of magnitude larger than the Stokes drift velocity. Mellor shows then that the classic set-down result is recovered (or very nearly so) only if vertical turbulence mixing is included.

Ponte and Klein (2013) devise a potentially very useful method of reconstructing upper-ocean potential vorticity (PV; from surface to $\sim 500 \mathrm{~m}$ ), hence the mesoscale eddy field, from a knowledge of the sea surface height anomaly. The method extends a previous PV inversion method by Lapeyre and Klein (2006) to situations when signatures of surface density anomalies (say due to SST anomalies) to eddy dynamics are weak, and it is tested using the eddy field that results from a baroclinically unstable, initially zonal flow in an idealized channel. The method relies on a statistically derived correlation between PV at depth and PV anomalies at a reference level, and on relating the regression to background PV gradients which in practice can be estimated from observations (e.g., ARGO floats).
Exarchou et al. (2012) propose the parameterization of diapycnal diffusivity in a global ocean model depending on the intensity of tidal energy dissipation over rough topography. They examine the sensitivity of the circulation simulated by the model to the tidal mixing scheme using different spatial scales of the bottom roughness. The dependence of the topographic spectra with depth influences the vertical profile of the diffusivity, leading to different equilibrium solutions in the Atlantic Meridional Overturning Circulation and bottom circulation.

Gao et al. (2013) modeled the circulation in the Gulf of Tonkin using the Princeton Ocean Model forced by surface and lateral boundary conditions and tidal forcing. The Gulf is located in the northwestern region of the South China Sea between China and Vietnam. The Gulf is rich in oil and biological resources, but observations of the circulation are limited. From the model results, the authors show the seasonality of the circulation and indicate the significance of inflow from the South China Sea.

The Yellow River transports a huge amount of sediment into the Bohai and Yellow Seas. Understanding the sediment transport process is of great importance for the coastal environmental management issues. Lu et al. (2013) analyze the ocean circulation and its associated sediment variation in the Bohai and Yellow seas using a coupled wave-tide-circulation model. They demonstrate that the sediment flux is primarily driven by the buoyancy forcing of the Yellow River freshwater discharge and modulated by the wind-driven surface wave and circulation patterns in the region.

Wang et al. (2013a) use a high-resolution circulation model to investigate the responses of the southwestern Yellow Sea to tidal and wind forcing. The authors find that the quadratic nature of the bottom friction is a crucial factor in explaining the weaker influence of the Eulerian tidal residual currents on the Lagrangian trajectories. As a result, the Lagrangian trajectories do not follow the Eulerian residual velocity fields in the shallow coastal regions.

Wang et al. (2013b) evaluate the results of two different Ocean General Circulation Models, OFES from JAMSTEC and BRAN2.1 from the Bluelink collaborative project between CSIRO and the Royal Australian Navy. They found that while the annual transports of the East Australian Current computed from the models agree well with the observed estimates, the seasonal variations show considerable differences. Because of data assimilation, the BRAN2.1 generally gives a better temperature field. The authors also conclude that heat transport across the open boundaries contribute significantly to the regional heat budget.

Wu and Wang (2013) analyze the NCEP Global Ocean Data Assimilation System (GODAS) products to study the differences in the simulated evolution patterns between two types of El Niño, i.e., the eastern Pacific El Niño and the El 
Niño Modoki. The results suggest that east-west oscillation of the thermocline in the equatorial Pacific can be seen for the El Niño Modoki cases, while the eastern Pacific El Niño experience an additional north-south seesaw oscillation of the thermocline between approximately $15^{\circ} \mathrm{N}$ and $15^{\circ} \mathrm{S}$, which is forced by the wind stress curl pattern over the west-central Pacific.

We wish to thank our hosts, Profs. Masumoto and Miyazawa, and scientists and staff of JAMSTEC for their warm hospitality and help during the workshop. LYO wishes to thank Prof. Miyazawa in particular for his tremendous effort and hard work in preparations for the workshop. We also thank the Chief Editor Prof. Jörg-Olaf Wolff of Ocean Dynamics for help and encouragements throughout the process of preparing this Topical Collection. Last but not least, we thank all the reviewers for their help in ensuring that the submitted manuscripts are held to the highest standard.

\section{References}

Exarchou E, von Storch J-S, Jungclaus J-H (2012) Impact of tidal mixing with different scales of bottom roughness on the general circulation. Ocean Dyn 62:1545-1563. doi:10.1007/s10236-012-0573-1

Ezer T, Oey L-Y (2010) The role of the Alaskan Stream in modulating the Bering Sea climate. J Geophys Res C04025 doi: 10.1029/ 2009JC005830

Ezer T, Oey L-Y (2013) On the dynamics of strait flows: an ocean model study of the Aleutian passages and the Bering Strait. Ocean Dyn 63: 243-263. doi:10.1007/s10236-012-0589-6
Gao J, Xue H, Chai F, Shi M (2013) Modeling the circulation in the Gulf of Tonkin, South China Sea. Ocean Dyn 63:979-993. doi:10.1007/ s10236-013-0636-y

Goh G, Noh Y (2013) Influence of the Coriolis force on the formation of a seasonal thermocline. Ocean Dyn 63:1083-1092. doi:10.1007/ s10236-013-0645-x

Lapeyre G, Klein P (2006) Dynamics of the upper oceanic layers in terms of surface quasigeostrophy theory. J Phys Oceanogr 36:165-176

Longuet-Higgins MS, Stewart RW (1964) Radiation stresses in water waves; a physical discussion with applications. Deep-Sea Res 11: $529-562$

Lu J, Qiao F, Wang X, Teng Y, Jung KT, Liu Y (2013) Modeling the Yellow River sediment flux and its deposition patterns under climatological conditions. Ocean Dyn 63:709-722. doi:10.1007/s10236013-0626-0

Mellor G (2013) Waves, circulation and vertical dependence. Ocean Dyn 63:447-457. doi:10.1007/s10236-013-0601-9

Miyama T, Miyazawa Y (2013) Structure and dynamics of the sudden acceleration of Kuroshio off Cape Shionomisaki. Ocean Dyn 63: 265-281. doi:10.1007/s10236-013-0591-7

Phillips OM (1977) The dynamics of the upper ocean. Cambridge University Press, Cambridge, p 336

Ponte AL, Klein P (2013) Reconstruction of the upper ocean 3D dynamics from high-resolution sea surface height. Ocean Dyn 63:777-791. doi:10.1007/s10236-013-0611-7

Wang B, Hirose N, Moon J-H, Yuan D (2013a) Difference between the Lagrangian trajectories and Eulerian residual velocity fields in the southwestern Yellow Sea. Ocean Dyn 63:565-576. doi:10.1007/ s10236-013-0607-3

Wang X-H, Bhatt V, Sun Y-J (2013b) Study of seasonal variability and heat budget of the East Australian Current using two eddy-resolving ocean circulation models. Ocean Dyn 63:549-563. doi:10.1007/ s10236-013-0605-5

Wu C-R, Wang L-C (2013) Contrasting the evolution between two types of El Niño in a data assimilation model. Ocean Dyn 63:577-587. doi:10.1007/s10236-013-0610-8 